\title{
General practice partnerships: till death us do part?
}

\author{
Neil G Snowise
}

\begin{abstract}
Objectives-To investigate applications for general practice partnership vacancies by established general practitioner principals, the reasons for changing partnerships, and the disincentives to these moves.
\end{abstract}

Design-Confidential postal questionnaire.

Subjects-Applicants to 367 general practices in the United Kingdom advertising for a new full time partner.

Main outcome measures-The proportion of job applications containing at least one application from established principals, proportion of principals appointed as new partners, incentives and disincentives to changing partnership.

Results-Of 325 replies (89\% response rate) received, 292 were suitable for further analysis. $210 / 241(87 \%)$ of all applications contained some applications from at least one established principal. $12 \%$ of all applications were made by principals. 41/296 (14\%) of the newly appointed partners had previously been an established principal. The main reasons for leaving the previous partnership were a desire to move locality or not getting on with previous partners. The disincentives to changing partnerships were largely financial, including the cost of the move and loss of income.

Conclusions-It is possible for established principals in general practice to overcome the disincentives and to change partnerships. There did not seem to be any overall prejudice against appointing principals, in contrast to previously published views.

\section{Introduction}

Partnerships in general practice in the United Kingdom are usually viewed as long term posts. It has been stated that it is almost impossible for an established general practitioner principal to change practice, and it is usually viewed as inevitable that when doctors accept a partnership they will have to remain there for the rest of their life.' This lack of job mobility is said to trap many doctors. ${ }^{2}$ These statements are opinions, however, not the results of analyses. Although several papers discuss methods of recruiting new partners in general practice, ${ }^{34}$ they do not consider the concept of offering partnerships to a previously established principal.

The difficulty of general practitioners working in the NHS in relocating has important implications for primary health care in Britain. The lack of published data, apart from personal viewpoints, concerning the desire or ability of principals to change partnerships is therefore surprising.

This study was designed to determine what proportion of applications to advertised partnership vacancies in the United Kingdom are from general practitioners already established as principals. The study also aimed to determine what proportion of practices seeking a new partner appointed an established principal. A subsidiary aim was to determine why established principals wanted to change practice and the main disincentives and difficulties encountered.

\section{Methods}

Practices seeking new partners were identified from the "Partnerships Offered" section of the BMF's advertisements. Questionnaires were sent to these practices for a pilot study in November and December 1990 and to all practices advertising vacancies in the issues of 12 January 1991 to 4 May 1991 inclusive. A confidential postal questionnaire was sent to these practices three to four months after the first advertisement appeared, and one postal reminder was sent to all non-responders. The questionnaire requested details about the practice and the new and the departing partners.

The study was restricted to partnerships looking for a new full time partner and excluded single handed practices; part time and job share vacancies; salaried partners or assistants; and also advertisements with box numbers or with no postal address given.

Practices that appointed a new partner who was previously an established principal were identified from the completed questionnaires. A further questionnaire was sent to new partners who had previously been principals, followed by one postal reminder to non responders. This further questionnaire requested details about the doctor, his or her previous practice, and the reasons for changing partnerships.

\section{Results}

\section{RECRUITMENT}

Of 367 questionnaires sent to practices advertising for a new partner, 262 (71\%) practices replied, increasing to $325(89 \%)$ replies after one reminder. Thirty three replies were subsequently omitted from further analysis because a part time partner or no partner had been appointed, leaving 292 valid replies for analysis relating to 296 new partners (four practices appointed two partners).

Not all respondents answered all the questions; the number of responders is stated throughout.

The 296 vacancies were due to the appointment of 270 replacement partners (table I) and 26 additional partners. A total of 38 (14\%) of the 270 departing partners left to join another practice.

\section{APPLICATIONS FOR VACANCIES}

The mean number of applications for each partnership vacancy was 31 and the range is shown in table II. Two hundred and forty one $(83 \%)$ respondents gave both the total number of applicants and the number of established principals who applied for the vacancy. The total number of applications was 7851 , of which 
$933(12 \%)$ were from established principals. A total of 210 of the applications to these 241 practices $(87 \%)$ contained at least one application by an established principal.

TABLE I-Reasons for partners leaving

\begin{tabular}{lc}
\hline & No $(\%)$ of practices $(\mathbf{n}=270)$ \\
\hline Retiring or reducing commitment & $134(50)$ \\
Changing career & $4512^{\star}(17)$ \\
Joining another practice & $38(14)$ \\
Emigrating or working abroad & $17(6)$ \\
Women partners: & $9(3)$ \\
Relocating with husband & $91 / 2^{\star}(4)$ \\
Family commitments & $9(3)$ \\
Died & $5(2)$ \\
Retiring owing to ill health & $3(1)$ \\
Not stated & \\
\hline
\end{tabular}

* Two partners reduced their commitment to create one full time vacancy.

TABLE II -Applications for partnership vacancies

\begin{tabular}{lcc}
\hline $\begin{array}{l}\text { No of applications } \\
\text { per vacancy }\end{array}$ & $\begin{array}{c}\text { No of partnership } \\
\text { vacancies }(\mathbf{n}=292)\end{array}$ & $\begin{array}{c}\% \text { (No) of vacancies with } \\
\text { applications from established } \\
\text { principals }\end{array}$ \\
\hline $0-10$ & 12 & $75(8 / 12)$ \\
$11-20$ & 63 & $80(47 / 59)$ \\
$21-30$ & 73 & $88(58 / 66)$ \\
$31-40$ & 50 & $96(44 / 46)$ \\
$41-50$ & 32 & $89(24 / 27)$ \\
$56-60$ & 23 & $95(20 / 21)$ \\
$\geqslant 61$ & 14 & $90(9 / 10)$ \\
Not stated & 25 & \\
\end{tabular}

^Some practices did not state whether principals had applied.

\section{PARTNERSHIP MOVES BY ESTABLISHED PRINCIPALS}

Of the 296 partners who were newly appointed, 41 (14\%) had previously been an established principal in another practice; $29(71 \%)$ were aged between 31 and 40. Thirty six of these principals completed further questionnaires ( $89 \%$ response rate). The time spent in the previous practice and also the time to parity within the new partnership varied considerably (table III).

TABLE III-Characteristics of 36 previously established principals

\begin{tabular}{lc}
\hline & No \\
\hline Time with previous practice: & \\
6 months-1 year & 4 \\
1-2 years & 12 \\
21/2-5 years & 9 \\
$5-9$ years & 11 \\
Time to parity in new partnerships: & 8 \\
$0-6$ months & 11 \\
$1-2$ years & 17 \\
$21 / 2-31 / 2$ years & \\
\hline
\end{tabular}

\section{REASONS FOR CHANGING PARTNERSHIPS}

The reasons for leaving a previous partnership were indicated by a choice of five statements (table IV); more than one reason could be chosen. Among the other factors mentioned were excessive workload, too onerous on call rota, inner city locality, and incompatibility with the organisation or philosophy of the practice (training or fundholding, for example).

TABLE IV-Reasons for leaving previous partnership (36 general practitioners)

\begin{tabular}{lc}
\hline & No of replies \\
\hline Wanted to move geographically & 14 \\
Spouse was moving job or area & 2 \\
Did not get on with my partners & 10 \\
Income was inadequate & 9 \\
Other reasons & 24 \\
\hline
\end{tabular}

\section{DISINCENTIVES TO CHANGING PARTNERSHIPS}

Twenty one of $36(58 \%)$ respondents were concerned about the financial effect of their move, particularly loss of a parity income, but $30(83 \%)$ expected their income to recover in two to three years. Other major concerns were the social consequences of moving, including the stress of moving, uprooting the family (with the possible loss of spouse's job), and leaving friends. Other concerns included difficulties in asking for references and working the required period of notice in partnership agreements, the uncertainty of change, and the fear of failure.

\section{Discussion}

This study found that $14 \%$ of the newly appointed partners had previously been a partner in another practice and $14 \%$ of the departing partners left to join another practice. These findings suggest that more established general practitioners change partnerships during their careers than previous authors have claimed. Furthermore, the proportion of applications from established principals was similar to the proportion in which they were appointed. This finding does not support any assertions of prejudice against this group.

Although this study attempted to obtain data on nationally advertised vacancies and achieved a high response rate, the results may not be representative. Many practices appoint a new partner without advertising, and single handed practices, for which family health services authorities make the appointment, were excluded from this study. However, a random survey by letter of 13 family health services authorities in England and Wales carried out to ascertain details of principals admitted to their lists in 1991 showed that these authorities admitted a total of 171 full time principals, of whom $26(15 \%)$ had previously been principals (excluding any 24 hour retirement posts).

Established principals can bring the benefit of their experience to a new practice and may have a much better idea of what they are looking for and more awareness of what factors would ensure a successful partnership in the future.' In no other profession do keen, highly trained executives expect to leave the same job in their 60s that they entered in their 30s.

Remaining in the same practice until retirement does not necessarily offer the best in terms of personal development or patient care. If there is personal dissatisfaction, low morale, or professional frustration, the knowledge that a move is unlikely to be achieved can only aggravate the problems. Most general practitioners are further restricted by needing to live within the practice area, preventing residential relocation.

The study findings suggest that the main disincentives to changing partnerships are financial. This could partly be remedied if experience was recognised so that a parity income was preserved or more rapidly regained. Unfortunately the new contract for general practitioners does nothing to facilitate movement of general practitioners between practices, although some suggestions have been published with this aim. The introduction of term contracts for a fixed number of years was met with wide interest, ${ }^{5}$ and more recently a "portable" basic practice allowance was suggested. ${ }^{2}$ I am not proposing that all general practitioners should consider moving partnerships. Nevertheless, one in seven newly appointed partners in this study were previously established principals, and more research is needed to determine if a greater number would like to change partnership. The profession may need to explore ways in which changing partnerships could be made easier.

This study was funded by a grant from the Clare Wand Fund. I thank all the doctors who participated in the study. Dr Norman Beale and Professor Raymond Illesley provided 
valuable advice throughout the study. I am also grateful to the staff of the medical library, Post Graduate Medical Centre, Royal United Hospital, Bath, and the librarians of the Royal College of General Practitioners.

1 Side CD. Appointment and mobility of general practitioners. BMf 1987;294: $1265-6$
2 Richards C. General practice as a career. $B M 7$ 1991:303:827-8.

3 Key I. Recruiting new principals in general practice. $B M \mathcal{F} 1985: 291: 451-5$.

$4 \mathrm{King} \mathrm{J}$, Whitfield $M$. How to choose a new partner in general practice. $B M \gamma$ 1990;301:1258-60.

5 Macleod J. Appointment and mobility of general practitioners. BMJ 1987; 295:54.

(Accepted 8 fuly 1992)

\section{Partners in Practice}

\section{Caring for the future}

\section{Martin Lawrence}

This is the fourth of a series of articles focusing on the current tasks and functions of the primary health care team

\section{Department of Public}

Health and Primary Care,

University of Oxford, Radcliffe Infirmary, Oxford OX2 6HE

Martin Lawrence, regional health authority lecturer in general practice

BMF 1992;305:400-2
We live in a time of massive change. Primary care is no exception. Having practised in a relatively stable structure since 1948, general practitioners have been affected in the past five years by various government

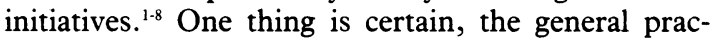
titioner is no longer going to be left to practise independently and in isolation. The demand is for accountability - to patients with needs, to a profession dedicated to assuring quality, and to a society which sets targets for effective and efficient care, where possible justified by research. The three areas of accountability are interrelated and the key to satisfying them is partnership.

\section{Patients as partners}

It is 40 years since Collings described a practice which had to lock up and bar the door "to stop the patients coming in," and since the 1966 charter general practice has had the time to evaluate care from a patient orientated standpoint. ${ }^{10}$ Byrne and Long described "doctors talking to patients" et al emphasised the need to consider patients' ideas and concerns ${ }^{12}$; but only by 1985 did Tuckett et al acknowledge that the consultation is as much the patient's as the doctor's. ${ }^{13}$

Direct assessment of patients' views and needs has been more difficult to achieve.

Patient participation groups were officially recognised in 1972. ${ }^{14}$ They were established with four main objectives: to provide feedback in the planning and evaluation of services; to work with the practice in providing health education for patients (for example, in open meetings or by staffing a patients' library); to act as a safety valve for the transmission and discussion of complaints; and to provide social support (for instance, help with transport for infirm patients). Evaluation of the groups emphasised their enthusiasm but noted that only small proportions of patients participated in the groups. ${ }^{15}$

Community health councils were established in 1975 to provide the patients' viewpoint in planning of the health service. While there was no clear structure for them to use in their early years, the increased role of family health services authorities in planning services has now enabled community health councils to be represented, and many medical audit advisory groups are working with the councils as representatives of patients' views.

The importance of patients' views in audit of care is emphasised by the new contract and encouraged by family health services authorities and medical audit advisory groups. Evaluation is difficult, not least because patients tend to be oversupportive, even in the face of inadequate care,${ }^{16}$ and instruments for eliciting views are currently scarce, usually not well validated,

\section{Needs for research and development}

- In future it will be necessary to base care on targets and guidelines justified by research evidence

- Adequate tools are required for assessment of patients' needs by the primary health care team

- Research on developing criteria for referral to hospital will enable the development of jointly agreed guidelines between primary and secondary care for the management of common conditions

- There is a need for a mechanism to ensure that the results of research carried out by academic departments are reflected in practice

or overcomplicated. Several bodies, both private, ${ }^{17}$ charities, ${ }^{18}$ and academic bodies, ${ }^{19}$ are currently attempting to correct this deficiency.

\section{Assessment of need}

Closely allied to the objective of eliciting patients' views is that of assessing need. Patients are able to criticise the care they are receiving, but it is difficult for them to formulate an unmet need. Any assessment by primary care teams is likely to be partial, owing to lack of expertise in developing instruments for assessment and time and incentive for applying them. To integrate this type of assessment with that of public health physicians would be more informative and realistic.

An example would be the assessment of elderly people. As imposed on practices in the general practitioners' contract this is probably ineffective, but carried out by using the advice of community geriatricians and established tools for assessment ${ }^{2021}$ it could provide a valid and reliable assessment of need..$^{22}$

\section{Partnership in the primary health care team}

Total quality management implies that each part of any service is examined by the person concerned with a view to improvement. The primary health care team is ideally placed to undertake such a process.

Consider the management of diabetes. Common failings (with possible solutions) are: inability of patients to make and remember appointments several months ahead (a receptionist can be responsible); deficient review of housebound patients (the district nurse can be involved); feet are not examined (the practice nurse's protocol can be adjusted); glucose control may be poor (the doctor must review the patient's management). At each stage a person from a different discipline knows best how to resolve a problem, what targets are attainable, and what to monitor in order to evaluate success. Practices are 